\title{
ESTUDO SOBRE A APLICAÇÃO FOLIAR DE ACIBENZOLAR-S-METIL PARA INDUÇÃO DE RESISTENCIA À FERRUGEM ASIÁTICA EM SOJA E CERCOSPORIOSE EM MILHO
}

\author{
R. Barros* \\ Universidade Federal da Grande Dourados. CP 533, CEP 79804-970, Dourados, MS, Brasil. E-mail: rbar- \\ rosufms@yahoo.com.br
}

RESUMO

A resistência sistêmica adquira pode apresentar benefícios promissores para o manejo de diversas enfermidades de plantas. Nas culturas da soja e milho esta tática poderia trazer benefícios como a redução de danos e também de custos de produção. Com o intuito de avaliar os efeitos da aplicação do acibenzolar-S-metil (ASM) em plantas de soja e milho sobre o controle de Phakopsora pachyrhizi H. Sydow \& P. Sydow e de Cercospora spp. (C. zeae-maydis Tehon \& Daniels, C. zeina Crous \& U. Braun e C. sorghi var. maydis Ellis \& Everh), foram conduzidos quatro experimentos em campo com estas culturas. Em soja, foi realizado um experimento em Maracaju, MS, na variedade CD 219 RR com a aplicação de cinco tratamentos em diferentes programas de pulverização de herbicida, inseticidas e fungicidas com e sem a associação do ASM em diferentes estádios da cultura. Em milho, dois experimentos foram conduzidos na safrinha 2008 em Aral Moreira, MS, (híbrido Somma) e Maracaju, MS, (híbrido 2B710) com a aplicação de ASM isolado e em associação com azoxistrobina + ciproconazole em dois diferentes estádios de desenvolvimento das plantas. Outro ensaio com milho foi conduzido no verão de 2008/ 2009 com o híbrido AG 9040, em Maracaju, MS, também com a aplicação de ASM isoladamente e em mistura com azoxistrobina + ciproconazole com pulverizações em até três estádios diferentes das plantas de milho. Em nenhum dos experimentos conduzidos detectou-se benefícios da utilização do ASM tanto isoladamente quanto em mistura com fungicidas para o controle da ferrugem asiática em soja e da cercosporiose do milho, tendo havido controle apenas quando da utilização de fungicida químico independentemente da adição do ASM.

PALAVRAS-CHAVE: SAR, ferrugem asiática da soja, cercosporiose do milho, Glycine max L., Zea mays L., Bion.

\begin{abstract}
STUDY ON A FOLIAR APPLICATION OF ACIBENZOLAR-S-METHYL TO INDUCE RESISTANCE TO ASIAN RUST IN SOYBEANS AND GRAY LEAF SPOT OF MAIZE. Induced systemic resistance may present promising benefits for the management of various diseases of plants. In soybeans and corn this tactic could bring benefits such as reduction of damage and lower production costs. In order to evaluate the effects of the application of acibenzolar-S-methyl (ASM) on soybeans and corn for the control of Phakopsora pachyrhizi H. Sydow \& P. Sydow and Cercospora spp. (C. zeae-maydis Tehon \& Daniels, Zeina C. Crous \& U. Braun and C. sorghi var. Maydis Everh \& Ellis), four field experiments were conducted with these crops. In soybeans, the experiment was conducted in Maracaju/MS, Brazil, on the variety CD 219 RR with the application of 5 different treatments consisting of the spraying of herbicide, insecticides and fungicides with and without the association of ASM at different stages of the crop. In corn, 2 experiments were conducted in the 2008 off-season in Aral Moreira-MS (hybrid Somma) and Maracaju/MS (hybrid 2B710) with the application of ASM alone and in combination with azoxystrobin + cyproconazole at 2 different stages of plant development. Another test was conducted with corn in the summer of 2008/2009 with the hybrid AG 9040 in Maracaju/MS, also with the application of ASM alone and in combination with azoxystrobin + cyproconazole sprayed on up to 3 different stages of the corn plants. None of the experiments conducted showed benefits of using ASM either alone or in mixture with fungicides for the control of soybean rust and gray leaf spot in maize; only the use of chemical fungicides controlled the fungus, regardless of the addition of ASM.
\end{abstract}

KEY WORDS: SAR, Asian soybean rust, gray leaf spot of maize, Bion.

*Doutorando em Agronomia. 


\section{INTRODUÇÃO}

A aplicação de fungicidas químicos é uma das principais táticas de controle para evitar ou minimizar danos à produtividade nas culturas de soja (Glycine max L.), milho (Zea mays L.) e milho safrinha no Brasil.

No caso da soja, um dos principais alvos desta tecnologia é a ferrugem asiática causada pelo fungo Phakopsora pachyrhizi (H. Sydow \& P. Sydow) que de 2000 a 2008 encontrou nos fungicidas químicos a única medida de controle tecnicamente e economicamente viável.

Quanto ao milho, a utilização de fungicidas tem sido alicerçado principalmente pela falta de rotação de culturas em localidades com clima favorável à produção deste cereal, onde são realizadas até cinco safras a cada dois anos, entre cultivos de verão e safrinha, o que favorece o aumento de inóculo de vários patógenos e, em consequência, a severidade de doenças desta cultura, dentre elas a cercosporiose. Esta doença pode ser causada por três espécies de Cercospora, especialmente C. zeae-maydis Tehon \& Daniels e C. zeina Crous \& U. Braun e também C. sorghi var. maydis Ellis \& Everh. (WHITE, 2000; CROUS et al., 2006). Associado à falta de rotação, outro fator de grande relevância no incremento da intensidade de doenças no milho está relacionado aos programas de melhoramento, os quais têm concentrado seus esforços na obtenção de híbridos cada vez mais produtivos, minimizando a importância do controle genético sobre os patógenos associados a esta cultura. A utilização cada vez maior de fungicidas nas culturas da soja e milho tem proporcionado, além do aumento dos custos de produção, diversos outros problemas, como os relacionados a desequilíbrios biológicos, como a diminuição da incidência de fungos entomopatogênicos em pragas comolagartas, mosca-branca e ácaros, fazendo com que os produtores questionem a viabilidade do atual manejo de doenças destas culturas em médio prazo.

Neste sentido, uma das medidasque favoreceriam a manutenção da sustentabilidade do sistema de produção de soja e milho no país seria a utilização racional desses fungicidas químicos de forma integrada com outras medidas de controle, como a rotação deculturas, resistência genética e, mais recentemente, medidas promissoras como a indução de resistência.

Este sistema de resistência induzida, conhecido como resistência sistêmica adquirida(RSA), éeficiente contra diversos patógenos, agindo na estimulação de resistência sistêmica após a infecção por um patógeno (MorAes, 1998). A ativação deste sistema de defesa pode ser desencadeada por agentes, chamados elicitores, de caráter biótico ou abiótico que resultam na expressão de mecanismos de defesa relacionados à produção de substâncias tóxicas ao patógeno e/ou formação de barreiras estruturais que restringem a colonização dos tecidos (Gurgel et al., 2005). Dentre as substâncias encontradas nas plantas associadas com a indução da resistência, o ácido salicílico é uma das maisimportantes, representando o primeirocomposto derivado de planta como indutor da RSA, no entanto, em função de sua fitotoxicidade às plantas, o ácido salicílico, bem como seus análogos, não tem potencial para uso comercial (ARAújo et al, 2005).

Dentre os compostos sintéticos, o acibenzolarS-metil (ASM) tem apresentado ação na ativação da RSA em diversos hospedeiros como batata (Solanum tuberosum L.) (Benellietal., 2004), cacaueiro (Theobroma cacao L.) (SILVA et al., 2008), tomateiro (Lycopersicon esculentum Mill) (OBRADOVIC et al, 2005; Silva et al, 2007), cafeeiro (Coffea arábica L.) (Costa et al., 2007; PEREIRA et al., 2008a) e na própria soja para Septoria glycines Hemmi e Cercospora kikuchii Matsu \& Tomotasu (Dallagnol et al., 2006) e P. pakyrhizi (Debona et al., 2009). Por não apresentar atividade microbiana direta, acibenzolar-S-metil é caracterizado apenas como um indutor da RSA.

O presente trabalho objetivou avaliar a eficácia da pulverização foliar de acibenzolar-S-metil com e semassociaçãocomfungicidasquímicossobrePhakopsora pachyrhizi em soja e Cercospora spp. em milho.

\section{MATERIAL E MÉTODOS}

Foram conduzidos quatro experimentos para avaliar os efeitos da aplicação do acibenzolar-Smetil, um sobre soja, cujo alvo foi a ferrugem asiática (Phakopsora pachyrhizi), e três em milho visando a cercosporiose (Cercospora spp.)

$\mathrm{O}$ experimento sobre a ferrugem da soja foi conduzido em condições de campo no Município de Maracaju, MS (latitude $21^{\circ} 37^{\prime} 12^{\prime \prime}$, longitude $55^{\circ}$ $\left.08^{\prime} 22^{\prime \prime}\right)$. Para este fim, foi utilizada a variedade CD 219 RR semeada no dia 20 de dezembro de 2008 no espaçamento de $0,45 \mathrm{~m}$ entre linhas e densidade de semeadura de 12 sementes por metro.

Os tratamentos deste ensaio constam da utilização de um programa de aplicações de herbicida (glifosato), inseticidas (profenofós, profenofós + lufenuron e tiametoxam) e fungicidas (azoxistrobina + ciproconazole e ciproconazole) com e sem a associação do acibenzolar-S-metil, em diferentes estádios de desenvolvimento da soja conforme descrição na Tabela 1.

O delineamento experimental utilizado foi o de blocos ao acaso, com cinco repetições. Cada parcela constou de sete linhas de cultivo de soja, com sete metros de comprimento cada. Para fins de avaliação, foram analisadas as três linhas centrais de cada parcela com quatro metros cada, resultando em uma área útil de $5,4 \mathrm{~m}^{2}$. 
Tabela 1 - Tratamentos aplicados na variedade de soja CD 219 RR para avaliação do efeito do acibenzolar-S-metil no controle da ferrugem asiática da soja em Maracaju, MS, durante a safra de verão 2008/2009.

\begin{tabular}{|c|c|c|c|}
\hline $\mathrm{N}^{\mathrm{o}}$ & Tratamentos & Dose (g i.a.ha $\left.{ }^{-1}\right)$ & Época de aplicação (estádio da soja ${ }^{1}$ ) \\
\hline \multirow{3}{*}{1} & Glifosato & 540 & V3 \\
\hline & Profenofós & 100 & V5 \\
\hline & Profenofós + Lufenuron & $150+15$ & V8 \\
\hline \multirow{5}{*}{2} & Glifosato + Acibenzolar-S-Metil & $540+7,5$ & V3 \\
\hline & Profenofós+ Acibenzolar-S-Metil & $100+7,5$ & V5 \\
\hline & Profenofós + Lufenuron + Acibenzolar-S-Metil & $150+15+7,5$ & V8 \\
\hline & Azoxistrobina + Ciproconazol $^{2}+$ Acibenzolar-S-Metil $^{-}$ & $60+24+7,5$ & R1 \\
\hline & Ciproconazol + Tiametoxam² + Acibenzolar-S-Metil & $45+45+7,5$ & 28 dias após R1 \\
\hline \multirow{5}{*}{3} & Glifosato + Acibenzolar-S-Metil & $540+7,5$ & V3 \\
\hline & Profenofós & 100 & V5 \\
\hline & Profenofós + Lufenuron + Acibenzolar-S-Metil & $150+15+7,5$ & V8 \\
\hline & Azoxistrobina + Ciproconazol + Acibenzolar-S-Metil & $60+24+7,5$ & R1 \\
\hline & Ciproconazol + Tiametoxam + Acibenzolar-S-Metil & $45+45+7,5$ & 28 dias após $\mathrm{R} 1$ \\
\hline \multirow{5}{*}{4} & Glifosato & 540 & $\mathrm{~V} 3$ \\
\hline & Profenofós & 100 & V5 \\
\hline & Profenofós + Lufenuron & $150+15$ & $" \prime$ \\
\hline & Azoxistrobina + Ciproconazol + Acibenzolar-S-Metil & $60+24+7,5$ & R1 \\
\hline & Ciproconazol + Tiametoxam + Acibenzolar-S-Metil & $45+45+7,5$ & 28 dias após R1 \\
\hline \multirow{5}{*}{5} & Glifosato & 540 & V3 \\
\hline & Profenofós & 100 & V5 \\
\hline & Profenofós + Lufenuron & $150+15$ & V8 \\
\hline & Azoxistrobina + Ciproconazol & $60+24$ & R1 \\
\hline & Ciproconazol + Lufenuron & $45+45$ & 28 dias após R1 \\
\hline
\end{tabular}

${ }^{1}$ Ritchie et al. (1982) adaptado por YoRINORI (1996).

${ }^{2}$ Azoxistrobina + Ciproconazol e Ciproconazol + Tiametoxam adicionados de 600 mL.ha-1 de óleo mineral parafínico.

Neste experimento de soja foram realizadas quatro avaliações da severidade da ferrugem asiática nos estádios V8, R3, R5.3 e R5.5 utilizando-se uma escala diagramática para diminuir a variação da estimativa entre locais(Fig. 1).

Para isso eram avaliadas dez plantas por parcela, sendo obtida a severidade da doença no folíolo central de um trifólio do nó correspondente ao último nó da testemunha com a presença de trifólios (totalizando 10 folíolos por parcela). A partir dos dados de severidade foi calculada a área abaixo da curva de progresso da doença (AACPD). Além da severidade, foi realizada uma avaliação de desfolha em R6. Quanto à produtividade, foi medido o rendimento de grãos de soja em $\mathrm{kg}$ por hectare.

Os experimentos com milho foram conduzidos na safrinha 2008 e na safra de verão 2008/2009. Na safrinha 2008 foram conduzidos dois experimentos, um no Município de Aral Moreira, MS, com o híbrido triplo de milho Somma em espaçamento de $0,8 \mathrm{~m}$ entre linhas semeado em 3/3/2008 e outro em Maracaju, MS, com o híbrido simples de milho 2B710, também semeado em espaçamento de $0,8 \mathrm{~m}$ entre linhas com semeadura realizada em 8/3/2008. Os tratamentos e a época de aplicação destes dois experimentos constam na Tabela 2 .
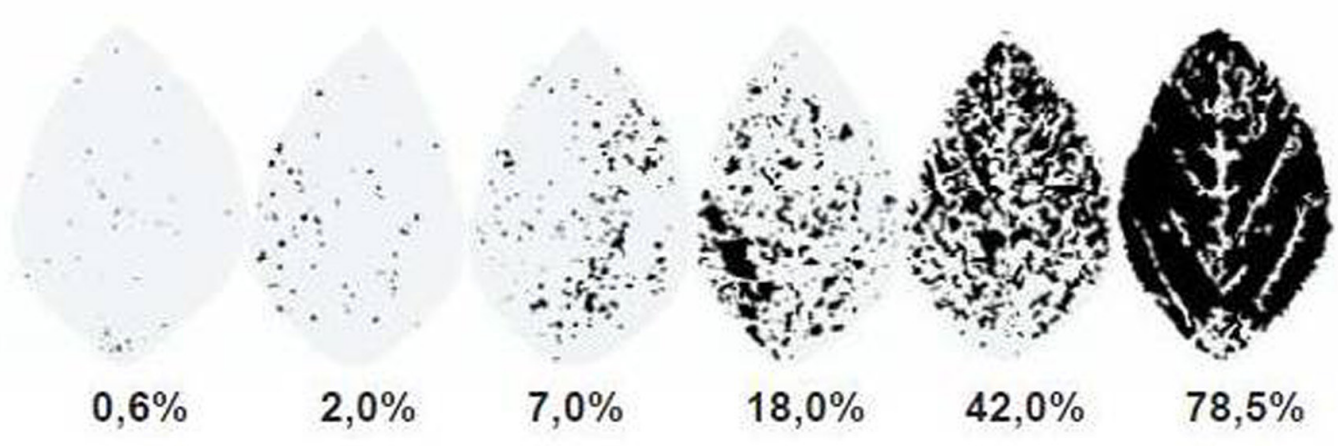

$2,0 \%$

$7,0 \%$

$18,0 \%$

$42,0 \%$

$78,5 \%$

Fig. 1 - Escala diagramática para avaliação da severidade da ferrugem-da-soja (GoDOY et al, 2006). 
O delineamento experimental utilizado nestes dois ensaios foi o de blocos ao acaso com cinco repetições. Cada parcela constou de quatro linhas de cultivo de milho, com sete metros de comprimento cada. Para fins de avaliação, foram analisadas as duas linhas centrais de cada parcela com quatro metros cada, resultando em uma área útil de $6,4 \mathrm{~m}^{2}$.

Outro ensaio em milho foi realizado na safra de verão 2008/ 2009 conduzido no Município de Maracaju, MS, com o híbrido simples de milho AG 9040, semeado no dia 15/12/2008 no espaçamento de 0,8 $\mathrm{m}$ entre linhas conforme tratamentos da Tabela 3.

As avaliações da severidade de doenças para o milho, tanto da safrinha como da safra de verão, foram realizadas sobre a cercosporiose cuja intensidade foi predominante em todos os experimentos. Para isto, foram avaliadas cinco plantas por parcela, sendo obtida a severidade da doença em cinco folhas por planta, a da espiga e duas abaixo e duas acima da inserção da espiga. Em todos os ensaios de milho estas avaliações foram realizadas aos 30, 45 e 60 dias após a aplicação do pré-pendoamento da cultura, a partir destes dados foi calculada a AACPD para a cercosporiose do milho. Além da severidade foi medido o rendimento de grãos de milho em $\mathrm{kg}$ por hectare.

Em todos os experimentos, os tratamentos foram aplicados através de um equipamento pulverizador costal manual de pressão constante, à base de gás carbônico, dotado de uma barra de pulverização com seis bicos do tipoleque duplo TJ 0611002 obedecendose a diluição de 160 litros de calda por hectare.

Todos os dados foram submetidos à análise de variância e ao teste $\mathrm{F}$ com significância $\alpha=0,05$. Quando F calculado foi maior que o F tabelado a análise teve prosseguimento com a aplicação do teste de comparação de médias Student-Newman-Keuls (SNK) ao nível de $5 \%$ de probabilidade, obtendo-se as diferenças mínimas significativas entre os tratamentos.

Tabela 3 - Tratamentos, dose e época de aplicação de fungicidas com e sem a adição do acibenzolar-S-metil visando o controle da cercosporiose em milho em Maracaju, MS, durante a safra de verão 2008/2009.

\begin{tabular}{clcc}
\hline$N^{\circ}$ & Tratamentos & Dose (g i.a.ha-1) & Época de aplicação (estádio do milho ${ }^{1}$ ) \\
\hline 1 & Testemunha & - & - \\
\hline 2 & Azoxistrobina + Ciproconazol ${ }^{2}$ & $60+24$ & V8 \\
\multirow{2}{*}{3} & Azoxistrobina + Ciproconazol & $60+24$ & V8 \\
& Azoxistrobina + Ciproconazol & $60+24$ & Pré-pendoamemto \\
\hline \multirow{2}{*}{5} & Azoxistrobina + Ciproconazol + Acibenzolar-S-Metil & $60+24+12,5$ & V8 \\
\hline \multirow{2}{*}{5} & Azoxistrobina + Ciproconazol + Acibenzolar-S-Metil & $60+24+12,5$ & Pré-pendoamemto \\
& Azoxistrobina + Ciproconazol + Acibenzolar-S-Metil & $60+24+12,5$ & V6 \\
\hline \multirow{2}{*}{6} & Acibenzolar-S-Metil & 12,5 & V8 \\
& Azoxistrobina + Ciproconazol + Acibenzolar-S-Metil & $60+24+12,5$ & Pré-pendoamemto
\end{tabular}

${ }^{1}$ V8 = estádio em que as plantas de milho estão com 8 folhas totalmente abertas.

Pré-pendoamento = estádio em que cerca de $10 \%$ das plantas expõem parte do pendão.

${ }^{2}$ MisturaAzoxistrobina + Ciproconazol adicionada de 600 mL.ha-1 de óleo mineral parafínico.

Tabela 3 - Tratamentos, dose e época de aplicação de fungicidas com e sem a adição do acibenzolar-S-metil visando o controle da cercosporiose em milho em Maracaju, MS, durante a safra de verão 2008/2009.

\begin{tabular}{|c|c|c|c|}
\hline $\mathrm{N}^{\circ}$ & Tratamentos & Dose (g i.a.ha-1) & Época de aplicação (estádio do milho ${ }^{1}$ ) \\
\hline 1 & Testemunha & - & - \\
\hline 2 & Azoxistrobina + Ciproconazol ${ }^{2}$ & $60+24$ & V8 \\
\hline \multirow{2}{*}{3} & Azoxistrobina + Ciproconazol & $60+24$ & V8 \\
\hline & Azoxistrobina + Ciproconazol & $60+24$ & Pré-pendoamemto \\
\hline 4 & Azoxistrobina + Ciproconazol + Acibenzolar-S-Metil & $60+24+12,5$ & V8 \\
\hline \multirow{2}{*}{5} & Azoxistrobina + Ciproconazol + Acibenzolar-S-Metil & $60+24+12,5$ & V8 \\
\hline & Azoxistrobina + Ciproconazol + Acibenzolar-S-Metil & $60+24+12,5$ & Pré-pendoamemto \\
\hline \multirow{3}{*}{6} & Acibenzolar-S-Metil & 12,5 & V6 \\
\hline & Azoxistrobina + Ciproconazol + Acibenzolar-S-Metil & $60+24+12,5$ & V8 \\
\hline & Azoxistrobina + Ciproconazol + Acibenzolar-S-Metil & $60+24+12,5$ & Pré-pendoamemto \\
\hline
\end{tabular}




\section{RESULTADOS E DISCUSSÃO}

No ensaio com soja, as condições ambientais na área experimental não foram favoráveis para a evolução dos sintomas da ferrugem asiática durante a maior parte do ciclo das plantas, fato que levou à ocorrência tardia da doença, embora o valor máximo de severidade na testemunha a tenha chegado a atingir 41\% em R5.5 (Tabela 4). Isto determinou a não ocorrência de grandes diferenças entre os tratamentos fungicidas quanto ao controle da doença. Estes se diferenciaram apenas em relação à testemunha tanto para a severidade em R5.3 e R5.5 e para a AACPD. O mesmo fato ocorreu para a desfolha em R6 cujos valores dos tratamentos fungicidas variaram de $67 \%$ a $69 \%$ contra $84 \%$ na testemunha, desfolha esta muito mais relacionada às condições climáticas desfavoráveis na área experimental no período próximo à maturação das plantas do que por influência da doença.

Desta forma, constata-se que para a severidade da ferrugem da soja, tanto em R5.3 quanto em R5.5e também para a AACPD, a inclusão do acibenzolar-Smetil (ASM) não proporcionou mudança no controle da doença em comparação ao tratamento isento da utilização deste composto em pulverização foliar (tratamento 5 - Tabela 4). SoARES et al. (2004) também não encontraram respostas positivas da utilização do ASM para o controle da bactéria Curtobacterium flaccumfaciens pv. flaccumfaciens (HedGEs) em feijoeiro comum. Da mesma forma, QUERINo et al. (2005) não observaram efeito positivo da utilização do ASM sobre o mal-do-Panamá em bananeira. Entretanto, em condições controladas e com a aplicação do ASM em tratamento de sementes, DeBOna et al. (2009) observaram efeito positivo deste indutor sobre a AACPD da ferrugem da soja. Em condições de campo Dallagnol et al. (2006) identificaram benefícios do uso de ASM sobre o controle das doenças de final de ciclo da soja (Cercospora kikuchii e Septoria glycines) melhorando inclusive a eficácia do fungicida difenoconazole em comparação a utilização deste triazol quando aplicado isoladamente. Comportamento semelhante foi observado por TöFoli; Domingues (2005) em tomateiro, onde comprovaram o aumento de eficácia dos fungicidas difenoconazole, azoxistrobina e mancozeb com a adição de ASM sobre o controle da pinta-preta (Alternaria solani Ellis \& G. Martin).

Quanto ao rendimento da soja, também devido provavelmente às condições climáticas, os patamares de produtividade não foram elevados e, dentre os tratamentos com aplicação de produtos, apenas aquele que não recebeu ASM apresentou produtividade estatisticamente superior à testemunha e aos demais tratamentos, com fungicidas que, em algum momento, receberam a adição do ASM (Tabela 4).
Nos experimentos de milho safrinha realizados em Aral Moreira, MS, e Maracaju, MS, sobre os híbridos Somma e 2B710, respectivamente, constataramse severidades da cercosporiosepermitindo obter AACPD satisfatoriamente suficientes para se fazer boas inferências sobre o desempenho dos tratamentos quanto ao controle da doença (Tabelas 5 e 6). Desta forma, nota-se que somente a aplicação do fungicida azoxistrobina + ciproconazole proporcionou controle aceitável da cercosporiose, especialmente em aplicação no pré-pendoamento do milho. Com relação ao experimento de milho verão realizado sobre o híbrido AG 9040, nota-se que, embora a severidade da cercosporiose não tenha atingido patamares elevados, a adição do ASM ao fungicida testado não melhorou o controle da doença independente do momento de aplicação (Tabela 7).

Com isto, esses resultados corroboram os obtidos na cultura da soja, onde a adição do ASM não influenciou o controle da doença tanto quando utilizado isoladamente quando em mistura com o fungicida.

Em trabalhos encontrados na literatura (Sharathchandra et al., 2004; Cavalcanti et al., 2006) enfatiza-se que o benefício da utilização do ASM está relacionado ao seu momento de aplicação frente ao instante da infecção do patógeno em teste, haja vista que, após a aplicação, a planta leva um certo tempo para expressar as características de resistência inerentes a este estímulo. Por outro lado, o período de atuação deste estímulo é limitado, devendo-se, a partir daí, haver novo desencadeamento do processo.

Desta forma, existe a probabilidade de que, no caso dos experimentos ora conduzidos, não tenha havido a coincidência entre o período de atuação do ASM nas plantas de soja e milho com o momento da infecção destes hospedeiros por seus respectivos patógenos. Além disto, fatores como a dose do indutor a ser utilizada está diretamente relacionada com o sucesso em seu emprego (CAVALCANTI; RESENDE, 2005; SALES Junior et al., 2007; SOAREs et al., 2009), desta forma uma dose suficiente do indutor deve ser aplicada no momento mais propício à obtenção dos benefícios da indução de resistência devendo ser este, além da identificação do melhor momento para aplicação, os objetivos principais de novos estudos relacionados a utilização do ASM em grandes culturas como a soja e milho.

Os melhores patamares de produtividade do milho safrinha, nos ensaios que sofreram danos em função da cercosporiose, foram obtidos apenas quando da aplicação da mistura de fungicidas, independente da associação com o ASM ou não (Tabelas 5 e 6). No experimento de milho verão não houve diferenças de produtividade entre os tratamentos (Tabela 7). 
R. Barros

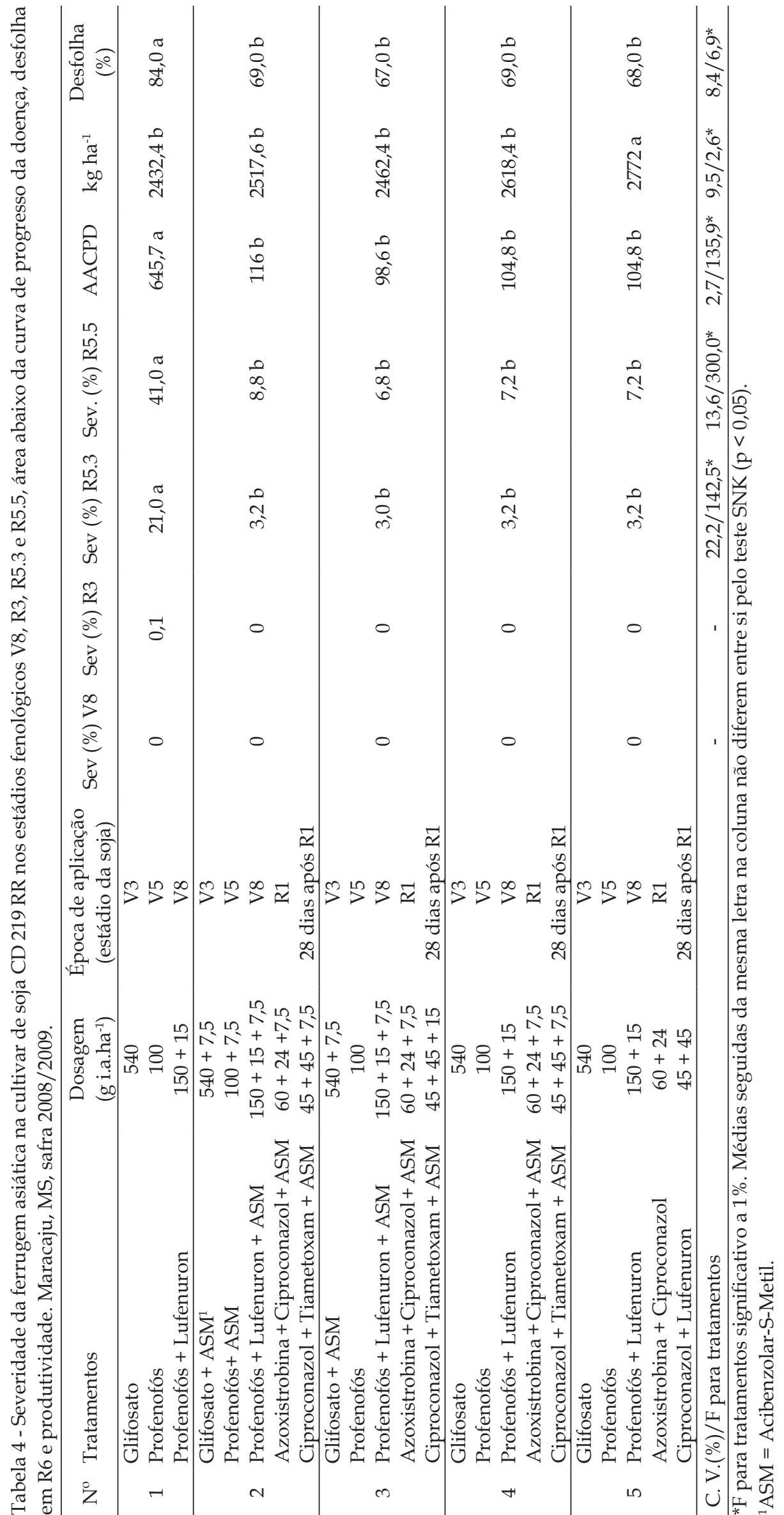



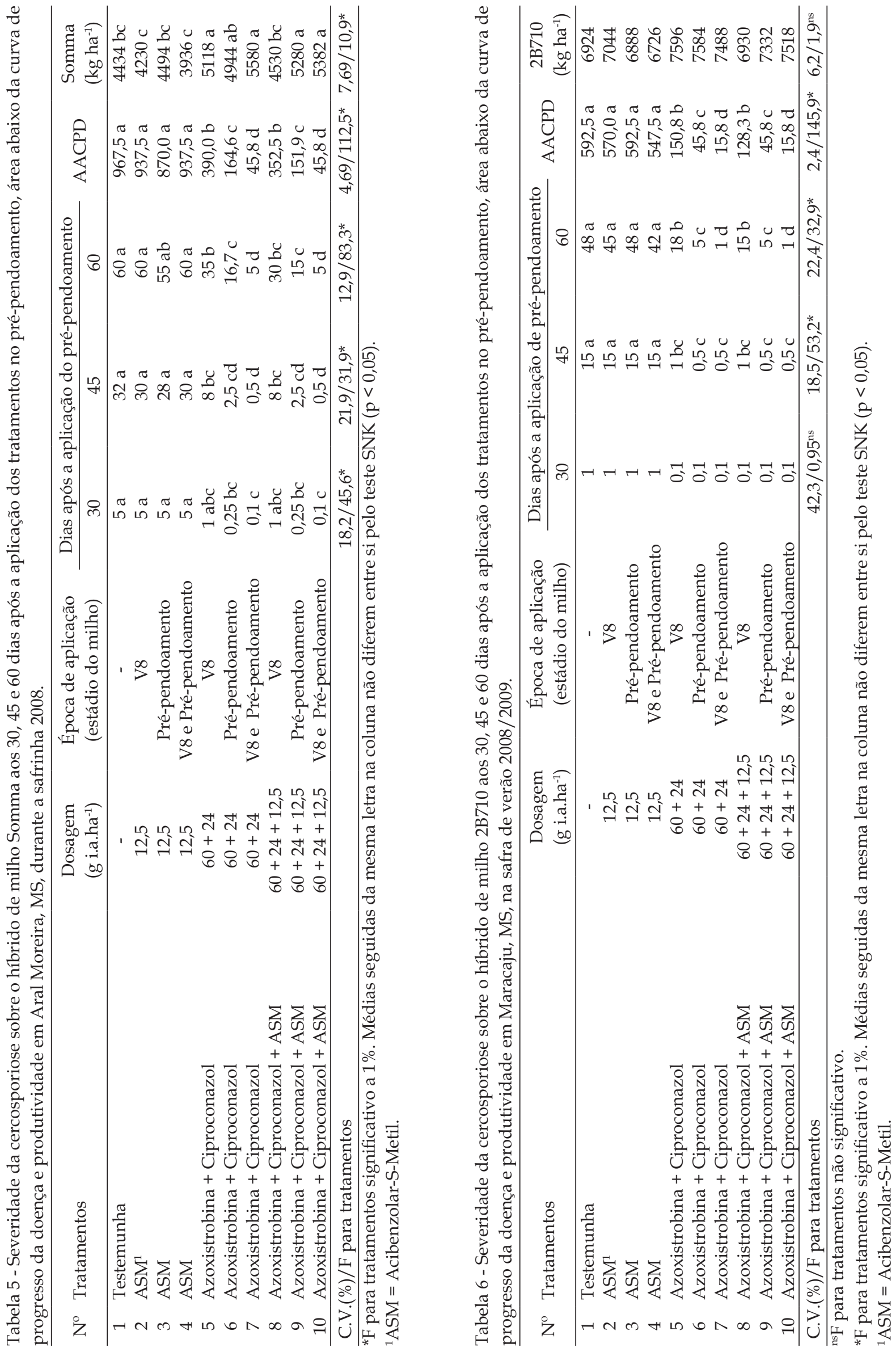


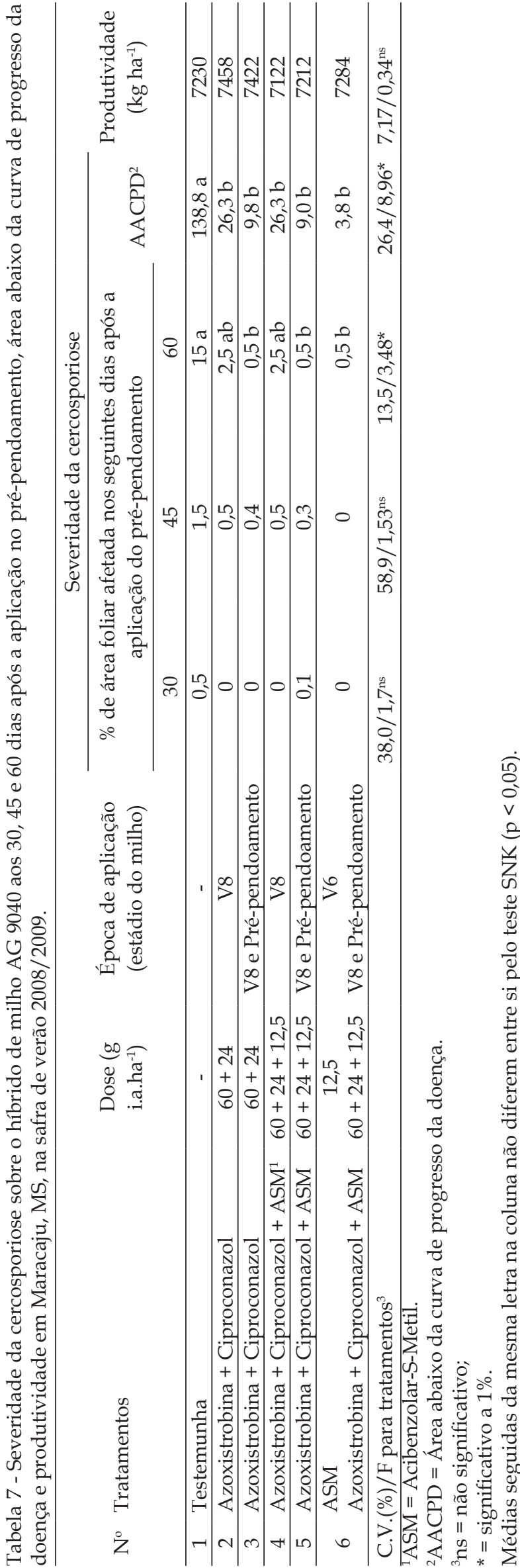

Um fato importante a ser observado é que nos dois experimentos de milho safrinha, quando se compara os rendimentos obtidos com azoxistrobina + ciproconazole em aplicação no estádio V8 da cultura com este mesmo tratamento, também aplicado em V8, mas com a adição do ASM, verifica-se um significativo dano à produtividade em decorrência da associação do fungicida com o ASM. Comportamento semelhante foi observado no estudo com soja, onde somente o tratamento com fungicidas, mas sem a utilização de ASM, foi estatisticamente superior à testemunha e aos demais tratamentos (Tabela 4). O acionamento dos mecanismos de resistência pelo ASM envolve o aumento na produção de uma série de proteínas como quitinases, peroxidades e polifenol oxidases (CAVALCANTI et al., 2006; IsHiDA et al., 2008; SiLva et al., 2007). A ativação destas proteínas requeridas para o acionamento da RSA pode desencadear um processo de competição com a produção de outras proteínas necessárias para processos básicos de desenvolvimento das plantas, comprometendo o seu crescimento normal. Efeitos de diminuição do crescimento e massa radicular de plântulas foram verificados por DeBONA et al. (2009) ao tratarem sementes de soja com ASM visando o controle da ferrugem asiática. Além da maior produção das enzimas anteriormente citadas, a ativação da RSA pelo ASM implica na maior lignificação da parede celular das células de plantas tratadas (IsHiDA et al., 2008; Pereira et al., 2008b) fenômeno que dificultaria a expansão celular e, por consequência, o crescimento normal das células.

De forma geral, pondera-se que a ausência de efeitos favoráveis à produtividade com a utilização do ASM, verificada neste trabalho, não exclui a possibilidade que este indutor de resistência em culturas como a soja e o milho possa trazer resultados positivos, considerando-se que ainda há muito a ser pesquisado sobre fatores que influenciam seu efeito como: variações ambientais, dose mais adequada de indutor para estas culturas e identificação do(s) melhor(es) momento(s) para sua aplicação, o que provavelmente deverá ocorrer de forma diferenciada de acordo com o material genético a ser utilizado tanto em soja como em milho.

\section{REFERÊNCIAS}

ARAÚJO, J.S. de P.; GONÇALVES, K. de S.; OLIVEIRA, B.C. de; RIBEIRO, R. de L.D. Efeito do acibenzolar-S-metil sobre a murcha-bacteriana do tomateiro. Horticultura Brasileira, v.23, n.1, p.5-8, 2005.

BENELLI, A.I.H.; DENARDIN, N.D.; FORCELINI, C.A. Ação do acibenzolar-S-metil aplicado em tubérculos 
e plantas de batata contra canela preta, incitada por Pectobacterium carotovorum subsp. atrosepticum atípica. Fitopatologia Brasileira, v.29, n.3, p.263-267, 2004.

CAVALCANTI, L.S.; RESENDE, M.L. V. Efeito da época de aplicação e dosagem do acibenzolar-S-metil na indução de resistência à murcha-de-verticillium em cacaueiro. Fitopatologia Brasileira, v.30, n.1, p.67-71, 2005.

CAVALCANTI, F.R.; RESENDE, M.L.V.; ZACARONI, A.B.; RIBEIRO JÚNIOR, P.M.; COSTA, J. de C.B.; SOUZA, R.M. Acibenzolar-S-metil e Ecolife na indução de respostas de defesa do tomateiros contra a mancha bacteriana (Xanthomonas vesicatoria). Fitopatologia Brasileira, v.31, n.4, p.372-280, 2006.

COSTA, M.J.N.; ZAMBOLIM, L.; RODRIGUES, F.A. Avaliação de produtos alternativos no controle da ferrugem do cafeeiro. Fitopatologia Brasileira, v.32, n.2, p.150-155, 2007.

CROUS, P.W.; GROENEWALD, J.Z.; GROENEWALD, M.; CALDWELL, P.; BRAUN, U.; HARRINGTON, T.C. Species of Cercospora associated with gray leaf spot of maize. Studies in Mycology, v.55, p.189-197, 2006.

DALLAGNOL, L.J.; NAVARINI, L.; UGALDE, M.G.; BALARDIN, R.S.; CATELLAM, R. Utilização de acibenzolar-S-metil para controle de doenças foliares de soja. Summa Phytopathologica, v.32, n.3, p.255-259, 2006.

DEBONA, D.; FIGUEIREDO, G.G.; CORTE, G.D.; NAVARINI, L.; DOMINGUES, L. da S.; BALARDIN, R.S. Efeito do tratamento de sementes com fungicidas e acibenzolar-S-metil no controle da ferrugem asiática e crescimento de plântulas em cultivares de soja. Summa Phytopathologica, v.35, n.1, p.26-31, 2009.

GODOY, C.V.; KOGA, L.J.; CANTERI, M.G. Diagrammatic scale for assessment of soybean rust severity. Fitopatologia Brasileira, v.31, p.63-68, 2006.

GURGEL, L.M.S.; OLIVEIRA, S.M.A. de; COÊLHO, R.S.B.; SILVA, R.L.X. da Proteção da murcha de fusário do tomateiro com acibenzolar-S-metil e ácido $\beta$-aminobutírico, em campo. Fitopatologia Brasileira, v.30, n.6, p.655-657, 2005.

ISHIDA, A.K.N.; SOUZA, R.M.; RESENDE, M.L.; CAVALCANTI, F.R.; OLIVEIRA, D.L.; POZZA, E.A. Rhizobacterium and acibenzolar-S-methyl (ASM) in resistence induction against bacterial blight expression of defese response in cotton. Tropical Plant Pathology, v.33, n.1, p.27-37, 2008.

MORAES, M.G. Mecanismos da resistência sistêmica adquirida em plantas. Revisão Anual de Patologia de Plantas, v.6, p.261-284, 1998.

OBRADOVIC, A.; JONES, J. B.; OLSON, S. M.; JACKSON, L. E.; BALOGH, B.; GUVEN, K.; IRIARTE, F. B.
Integration of biological control agents and systemic acquired resistence inducers against bacterial spot on tomato. Plant Disease, v.89, n.7, p.712-716, 2005.

PEREIRA, R.B.; ALVES, E.; RIBEIRO JÚNIOR, P.M.; RESENDE, M.L.V. de; LUCAS, G.C.; FERREIRA, J.B. Extrato de casca de café, óleo essencial de tomilho e acibenzolar-S-metil no manejo da cercosporiose-do-cafeeiro. Pesquisa Agropecuária Brasileira, v.43, n.10, p.1287-1296, 2008a.

PEREIRA, R.B.; RESENDE, M.L.V. de; RIBEIRO JÚNIOR, P.M.; AMARAL, D.R.; LUCAS, G.C.; CAVALCANTI, F.R. Ativação de defesa em cacaueiro contra a murcha-de-verticílio por extratos naturais e acibenzolar-S-metil. Pesquisa Agropecuária Brasileira, v.43, n.2, p.171$178,2008 b$.

QUERINO, C.M.B.; LARANJEIRA, D.; COELHO, R.S.B.; MATOS, A.P. de Efeito de dois indutores de resistência sobre a severidade do mal-do-Panamá. Fitopatologia Brasileira, v.30, n.3, p.239-243, 2005.

SALES JÚNIOR, R.; PONTES FILHO, F.S.T.; NUNES, G.H. de S.; TORRES, G.R. de C. Eficiência de acibenzolar-S-methyl e oxicloreto de cobre no controle de Acidovorax anenae subsp. Citrulli, agente causal da mancha-aquosa no meloeiro. Revista de Biologia e Ciências da Terra, v.7, n.1, p.66-70, 2007.

SHARATHCHANDRA, R.G.; NIRANJANRAJ, S.; SHETTY, N.P.; AMRUTHESH, K.N.; SHEKAR, S.H. A chitosan formulation Elexa indices downy disease resistence and growth promotion in pearl millet. Crop Protection, v.23, p.881-888, 2004.

SILVA, R.F.; PASCHOLATI, S.F.; BEDENDO, I.P. Indução de resistência em tomateiro por extratos aquosos de Lentinula edodes e Agaricus blazei contra Ralstonia solanacearum. Fitopatologia Brasileira, v.32, n.3, p.189-196, 2007.

SILVA, I.L. do S.S. da; RESENDE, M.L.V. de; RIBEIRO JÚNIOR, P.M.; COSTA, J. de C. do B.; CAMILO, F.R.; BAPTISTA, J.C.; SALGADO, S.M. de L. Efeito de nutrientes combinados com indutores de resistência na proteção contra a vassoura-de bruxa no cacaueiro. Ciência e Agrotecnologia, v.32, n.1, p.61-67, 2008.

SOARES, R.M.; MARINGONI, A.C.; LIMA, G.P.P. Influência de acibenzolar-S-methyl na indução de resistência de feijoeiro comum à murcha-de-curto bacterium. Fitopatologia Brasileira, v.29, n.4, p.373-377, 2004.

SOARES, A.C.F.; PEREZ, J.O.; SOUZA, C. da S.; GARRIDO, M. da S.; ALMEIDA, N.S. de Eficiência do acibenzolar-S-metil na proteção de plantas de inhame à Curvularia eragrostides. Revista Caatinga, v.22, n.2, p.115-118, 2009.

TÖFOLI, J.G.; DOMINGUES, R. J. Controle da pinta preta do tomateiro com o uso de acibenzolar-S-metil 
isolado e em mistura com fungicidas e em programas de aplicação. Arquivos do Instituto Biologico, São Paulo, v.72, n.4, p. 481-487, 2005.

WHITE, D.G. (Ed.). Compendium of corn diseases. 3.ed. St. Paul: American Phytopathological Society, 2000. 78p.
YORINORI, J.T. Cancro da haste: epidemiologia e controle. Londrina. EMBRAPA-CNPSo, 1996. (Circular Técnica 14).

Recebido em 6/9/10

Aceito em 31/10/11 